\title{
O Programa Minha Casa Minha Vida na Região Metropolitana de Fortaleza-CE: análise dos arranjos institucionais
}

\author{
Minha Casa Minha Vida Program in the Metropolitan Region of \\ Fortaleza: an analysis of institutional arrangements
}

Renato Pequeno Sara Vieira Rosa

\begin{abstract}
Resumo
Considerando o estado do Ceará, os resultados até aqui obtidos revelam a concentração dos conjuntos habitacionais do programa Minha Casa Minha Vida em alguns municípios metropolitanos, assim como a sua baixa disseminação pelos centros regionais habilitados à obtenção de recursos do Fundo de Arrendamento Residencial e do Fundo de Garantia por Tempo de Serviços. Diante desse quadro, buscou-se compreender as razões para a baixa efetividade do programa mediante a análise compreensiva dos arranjos institucionais, considerando o papel dos diferentes agentes envolvidos, notadamente as práticas dos setores empresarial imobiliário e da construção civil, as ações do Estado nas diferentes esferas de governo e os conteúdos dos instrumentos de planejamento e gestão do solo urbano e habitacional.
\end{abstract}

Palavras-chave: política habitacional; arranjos institucionais; construção civil; programa Minha Casa Minha Vida.

\begin{abstract}
Considering the State of Ceará (northeastern Brazil), the results obtained so far reveal the concentration of the housing estates of the Minha Casa Minha Vida Program in some metropolitan cities, as well as the low dissemination of the program across the regional centers authorized to obtain funding from Fundo de Arrendamento Residencial and from Fundo de Garantia por Tempo de Serviço (FGTS). In light of this panorama, we aimed to understand the reasons for the low effectiveness of the program through a comprehensive analysis of institutional arrangements, considering the role of the various actors involved, in particular the practices of the business, real estate and building sectors, the State's actions in the different spheres of government, and the contents of the instruments for planning and managing urban land and housing.
\end{abstract}

Keywords: housing policy; institutional arrangements; building sector; Minha Casa Minha Vida Program. 


\section{Introdução}

Neste artigo, pretende-se apresentar os resultados obtidos por meio de investigação científica realizada ao longo de 2013 e 2014, a qual teve como objeto de estudos os empreendimentos habitacionais construídos pelo Programa Minha Casa Minha Vida (PMCMV) na Região Metropolitana de Fortaleza (RMF) e entregues até o final de 2012. Realizada em rede junto a outros 11 núcleos de pesquisa de diferentes regiões brasileiras, a mesma teve como objetivos: - analisar o processo de implementação do PMCMV no nível local, verificando o papel dos agentes envolvidos em suas diferentes atribuições e interesses e a compatibilidade entre as políticas urbana e habitacional; - desenvolver uma análise do padrão de inserção urbana dos empreendimentos produzidos no âmbito do programa MCMV no território dos municípios selecionados, de forma a caracterizar o impacto urbano dos empreendimentos produzidos por meio do programa, notadamente sobre os padrões de segregação socioespacial vigentes, assim como sobre condições de acesso a oportunidades de desenvolvimento humano e econômico por parte dos moradores; - desenvolver estudos de natureza qualitativa, sobre empreendimentos selecionados que expressem diferentes situações de inserção urbana, visando identificar os impactos sociais e econômicos nas famílias beneficiárias do programa (Santo Amore, Rufino e Shimbo, 2015). Esses, por sua vez, se adequaram a três eixos temáticos: arranjos institucionais; condições de inserção urbana e segregação espacial; qualidade do projeto arquitetônico e urbanístico e impactos junto aos beneficiários.
Faz parte deste estudo a abordagem pluriescalar incluindo diferentes dimensões: a região (estado ou metrópole); o município, com destaque para os que que concentraram maior número de unidades habitacionais; o setor reunindo um conjunto de bairros, notadamente aqueles que concentram empreendimentos; 0 empreendimento, incluindo seu entorno; a unidade habitacional.

No caso deste artigo, pretende-se dar foco na análise do eixo que trata dos arranjos institucionais e dos instrumentos da política urbana e habitacional utilizados para a implementação do PMCMV na RMF. Partindo-se das questões norteadoras, adota-se como primeiro procedimento a identificação do quadro de atores envolvidos com a implementação do PMCMV na RMF, considerando as diferentes esferas de governo, as diversas modalidades em que o programa se subdivide e levando em conta as distintas escalas em que o mesmo se materializa. No caso, partimos de questões relacionadas às dificuldades de implementação do PMCMV no Ceará, assim como aos motivos de sua concentração espacial na RMF. Nesse sentido, destaca-se que a análise da distribuição espacial dos empreendimentos, assim como a avaliação do grau de satisfação dos moradores poderá ser obtida em outros trabalhos dos mesmos autores (Pequeno e Rosa, 2015).

Para sua realização destacam-se como procedimentos metodológicos: a análise geoestatística de bases de dados obtidas junto à Caixa Econômica Federal (CEF) considerando o quadro de empreendimentos aprovados até o final de dezembro de 2012; a condução de entrevistas semiestruturadas com os diferentes agentes envolvidos; a leitura crítica dos documentos obtidos junto às instituições 
diretamente envolvidos com a implementação do PMCMV; trabalhos de campo visando verificar in loco as condições de implementação.

Conforme proposto no projeto, as primeiras visitas serviram para que a pesquisa fosse apresentada às instituições envolvidas, em seus objetivos, procedimentos e resultados esperados, deixando claro o papel do grupo envolvido e o caráter exploratório dessa investigação. Da mesma forma, esclarecia-se o apoio do Ministério das Cidades, a abrangência nacional da pesquisa dada a sua realização em rede e os retornos a serem dados ao longo da mesma sob a forma de resultados preliminares.

Contudo, já nas primeiras visitas, o diálogo e a obtenção de informações foi extremamente fácil, considerando o conjunto de instituições públicas envolvidas. Com isso, a junção dos relatórios técnicos das políticas urbana e habitacional (nem sempre concluídos) com as informações fornecidas pelo Ministério das Cidades e pela CEF, referentes às localizações, empresas envolvidas, porte e prazos, facilitou as idas a campo para análise do conjunto de empreendimentos realizados na RMF.

Vale aqui mencionar que a RMF reúne atualmente 19 municípios estimando-se mais de 3,9 milhões de habitantes. Desses destaca-se um grupo de municípios conurbados a Fortaleza que totalizam quase $85 \%$ da população metropolitana: Aquiraz e Eusébio ao leste; Itaitinga, Pacatuba e Maracanaú ao sul; e Caucaia ao oeste. Em todos os demais verifica-se um padrão de urbanização dispersa, reconhecendo-se diversos núcleos urbanos em meio a um vasto território com características rurais.

Entretanto, no caso do PMCMV, observa-se que o programa se distribuiu de maneira diferenciada pelos municípios da metrópole. Primeiro, tem-se a concentração de empreendimentos nos municípios mais populosos como Fortaleza, Caucaia e Maracanaú, justamente onde se concentra a maior parte do déficit habitacional os quais correspondem ao alvo principal desta pesquisa; segundo, observa-se o conjunto de municípios situados no corredor industrial da BR 116, composto por Horizonte, Pacajus e Chorozinho, os quais apresentam ampla representatividade das unidades construídas pelo programa em relação ao total de domicílios; em seguida, no litoral leste, tem-se um agrupamento de quatro municípios onde as pressões do setor imobiliário e turístico trazem dificuldades para a produção habitacional de interesse social; no extremo sul, onde se encontra um núcleo urbano Maranguape e Guaiúba com maior predomínio de atividades rurais, poucos empreendimentos foram contratados; finalmente, no litoral oeste da RMF tem-se um conjunto de cinco municípios sob forte influência do complexo industrial e portuário do Pecém e da área de produção de petróleo em Paracuru: São Gonçalo, Paracuru, Paraipaba, Trairi e São Luis do Curu, os quais apesar da tendência de adensamento e da crescente demanda habitacional tiveram poucas unidades construídas (Pequeno, 2015).

Neste artigo, busca-se inicialmente caracterizar os agentes envolvidos em seus papéis, seus interesses, parcerias e conflitos, visando apresentar a situação existente do programa na RMF e no Estado do Ceará. Em seguida, são discutidos os resultados dessa investigação a partir da análise de alguns processos elencados. Por último, apontam-se algumas diretrizes com vistas a aprimorar o PMCMV no que se refere aos seus aspectos institucionais. 


\section{Os arranjos institucionais e os agentes da produção}

A análise do PMCMV no que se refere aos seus arranjos institucionais, presentes na implementação do PMCMV na RMF e no Ceará, requer a prévia compreensão do papel dos agentes sociais envolvidos, considerando seus interesses e em especial sua participação no processo de produção da cidade. No caso, é importante destacar a necessidade de reconhecer três tipos de agentes: - aqueles diretamente associados ao Estado, assumindo as diferentes atribuições do planejamento e da gestão do programa; - os que se incluem no setor empresarial, responsáveis pela incorporação, edificação e comercialização das unidades habitacionais; - o público-alvo, os quais podem ser desdobrados entre demandas individuais atendidas e demandas coletivas oriundas de remoções ou de movimentos sociais.

Quanto aos agentes do setor público diretamente vinculados ao Estado, vale mencionar as diferentes atribuições vinculadas às esferas de governo, indicando diversas responsabilidades e revelando discrepâncias na tomada de decisão. Na esfera federal de governo, é possível reconhecer o amplo papel da Caixa Econômica Federal como agente operador do PMCMV dada a sua capilaridade em direção aos estados e municípios através da Gidur (Gerência de Desenvolvimento Urbano). As reuniões realizadas com esse setor indicaram o modo diferenciado como as faixas eram atendidas pelo PMCMV bem como as dificuldades na contratação de empreendimentos da Faixa I, destacando-se dentre outros motivos: as precariedades urbanísticas em setores sem infraestrutura nem serviços; as condições de desenvolvimento institucional nos municípios; a especulação imobiliária.

Vale mencionar que esse setor passou por restruturação ao longo da pesquisa, subdividindo-se em Gihab (Gerência Executiva de Habitação) e Gigov (Gerência Executiva de Governo), em que a primeira se destina a projetos envolvendo o setor empresarial e a outra a projetos estritamente associados às demandas governamentais.

Da parte do Ministério das Cidades, verifica-se localmente que o mesmo se volta para uma atuação específica associada a grandes projetos, em que os processos decisórios requeiram maiores discussões e o montante de recursos envolvido seja maior. Vale destacar que ao longo da pesquisa presenciou-se a realização de seminário que tratou de ações voltadas para a construção de grandes conjuntos periféricos quando técnicos da ex-Gidur se opuseram à aprovação desses empreendimentos, dada a concentração dos mesmos num setor periférico desprovido de infraestrutura urbana e serviços. Vale destacar que esses empreendimentos estavam sob o comando dos governos estadual e do município de Fortaleza com o apoio do setor da construção civil, das concessionárias de infraestrutura urbana e mesmo algumas entidades dos movimentos sociais e de seus articuladores.

Quanto ao governo estadual observa-se que desde a extinção da Cohab as ações do governo tornaram-se cada vez mais reduzidas, buscando o mesmo se eximir de quaisquer responsabilidades neste setor (Cardoso, 2002). Todavia, com o aumento progressivo de recursos disponibilizados para habitação pelo Ministério das Cidades foi criada a Secretaria Estadual das 
Cidades, em 2007, estruturada em coordenadorias nos moldes do Ministério, exceção feita ao de mobilidade urbana.

Em sua composição, a Secretaria das Cidades do Ceará explicita o papel que a produção habitacional passou a apresentar nos últimos anos, indicando duas frentes: - a presença de coordenadoria de projetos especiais, em sua maioria voltados para o enfrentamento da questão da moradia mediante o reassentamento de famílias removidas de favelas em situação de risco ou comunidades próximas a projetos de grande porte realizados pelo governo; - a coordenadoria de habitação diretamente vinculada às ações do PMCMV, em suas diversas modalidades, para a qual as análises se concentram.

Dadas as dificuldades enfrentadas para que o PMCMV atingisse a meta pretendida de UHs no Ceará, a coordenadoria de habitação assumiu papel fundamental na condução de comitê interinstitucional. Um papel preponderantemente político visando implementar medidas que tornem a produção de UHs mais atraente para o setor da construção, ampliando recursos por UH, atendendo às demandas de empreiteiros e articulando junto às concessionárias a implementação de redes de saneamento.

Sobre o papel dos governos municipais observa-se que o PMCMV tem no município o recorte espacial principal tendo em vista a localização do empreendimento em relação aos instrumentos da política urbana, as atribuições que o mesmo assume em termos de aprovação, definição de critérios, formulação de demanda, acompanhamento e gestão do trabalho social. A análise do papel dos municípios, enquanto estrutura de poder foi realizada a partir das seguintes variáveis: - continuidade na gestão após mudança de governo; destaque dado ao setor habitacional no orçamento municipal; equipe, tanto no porte como na sua capacidade administrativa; - bases de dados disponíveis; disponibilidade e aplicabilidade de instrumentos da política urbana e habitacional; - intersetorialidade (Arretche, 2012).

No caso de Fortaleza, município com mais de 2,5 milhões de pessoas, houve um brusco rompimento na gestão municipal após as eleições de 2012, havendo ampla restruturação, substituindo secretários e promovendo o retorno de gestores, como no caso do setor habitacional. Na capital cearense o PMCMV encontra-se concentrado na Secretaria de Habitação Popular de Fortaleza (Habitafor). Com equipe bastante reduzida, suas atribuições até aqui se restringem à realização do trabalho social, visitando as famílias selecionadas e contribuindo na apresentação dos empreendimentos por ocasião da entrega das UHS e na organização dos condomínios. 0 papel dos técnicos vinculados a projetos e obras mostrou-se ainda mais restrito. Voltado às ações de planejamento e na perspectiva de ampliar o programa em Fortaleza mediante a implantação de grandes conjuntos, o setor pouco interfere na qualidade dos projetos arquitetônicos, muito menos na diversidade tipológica, na flexibilidade projetual e na progressividade da construção.

Fortaleza tem promovido a contratação de terceiros para a realização dos planos diretor municipal e local habitacional de interesse social como verdadeiro problema de origem. Na ausência de recursos humanos para a sua implementação e diante do precário controle social a ser efetuado pelos conselhos, esses tendem a ser subutilizados desde a sua aprovação, representando por vezes um mero 
certificado para acesso aos recursos vinculados às políticas específicas.

A intersetorialidade também se mostra em dificuldades. Por um lado, em função do quadro exíguo de técnicos; por outro, devido à concentração do PMCMV num mesmo órgão. Constatou-se que a divisão estanque entre as políticas urbana e habitacional, em que a primeira se encontra sob o comando da Secretaria de Urbanismo e Meio Ambiente e a segunda tendo à frente a Secretaria de Habitação, ampliam a dissociação entre as mesmas. Além disso, observa-se que a forma como a política urbana vem sendo conduzida revela alguns aspectos: o foco na regulamentação dos instrumentos que dinamizam o mercado imobiliário e induzem o desenvolvimento urbano segundo seus interesses; o engavetamento das zonas especiais de interesse social não havendo qualquer facilitação no acesso à terra urbanizada para empreendimentos habitacionais de interesse social.

Em Caucaia, onde vivem mais de 353 mil habitantes, o programa encontra-se numa coordenadoria especial vinculada ao gabinete do vice-prefeito, contando com a participação de técnicos das secretarias de planejamento urbano e de ação social. Tratando-se do segundo maior município do Estado, Caucaia tem seu crescimento demográfico diretamente associado ao transbordo de demandas oriundas de Fortaleza, as quais se agravam na ausência de uma política urbana metropolitana. Alvo de processos de planejamento urbano desde o final dos anos 1990, Caucaia remanesce sem uma política urbana definida, sendo seu plano diretor alvo de muitas mudanças e ajustes vinculados a projetos e interesses específicos do governo estadual, do setor industrial e em especial dos setores imobiliário e turístico.

Sendo um dos maiores municípios cearenses em superfície e possuidor de amplo déficit habitacional, Caucaia torna-se desde o início do PMCMV um dos principais alvos do setor da construção civil. Alguns fatores devem ser apontados para a expansão do programa nesse município nas suas primeiras fases: a agilidade na formulação de cadastro de demandas, a facilidade na obtenção de terrenos, os quais ainda que não fossem dotados de infraestrutura tinham na orientação da política municipal no sentido de contratar obras e mostrar resultados, compromisso na sua realização. Mesmo a intersetorialidade percebida especialmente com o apoio da secretaria de ação social merece ser destacada dado que esse corresponde ao setor mais importante em termos de poder municipal para que o programa venha a deslanchar.

Todavia, vale mencionar a fragilidade institucional reconhecida no porte da equipe, nas condições de acesso aos dados e na necessidade de contratação de serviços técnicos a terceiros para a realização dos instrumentos da política urbana e habitacional, os quais tendem a ser subutilizados.

Maracanaú corresponde ao terceiro maior município da RMF com mais de 221 mil habitantes, tendo no setor industrial sua principal atividade econômica. Sua criação se deu nos anos 1980 após a implantação de distrito industrial e a construção de milhares de unidades habitacionais no entorno do mesmo através do sistema BNH e Cohab-CE. Entretanto, só em meados dos anos 1990 que o setor industrial se consolida, trazendo consigo serviços e refletindo na conurbação junto a Fortaleza e na 
melhoria das condições das infraestruturas e serviços urbanos desse município.

Nesse município verifica-se uma situação bastante peculiar em termos de gestão municipal, evidenciando-se que a continuidade na administração faz maior diferença quando se tem um processo de planejamento em curso, assim como quando os processos de planejamento urbano e habitacional ocorrem no âmbito do setor público e menos dependentes de consultorias externas.

A partir de diálogos com técnicos responsáveis pelo setor de planejamento urbano, foi possível compreender a forma como se dá a atuação desse município adiante da questão habitacional. Revelou-se a associação entre o planejamento e o controle urbano, trazendo além disso o diferencial de formular estudos de viabilidade para novos empreendimentos, considerando os limites impostos pela legislação urbanística. Além disso, a disponibilidade de bases de dados, o georreferenciamento das informações e sua aplicação para o controle e a gestão do solo urbano trazem ao município um diferencial se comparado aos demais.

Considerando o PMCMV, observou-se que o município, no que se refere à faixa de interesse social, conta com coordenação específica, atuando na atribuição de critérios, na definição das demandas e na realização do trabalho social. Também tomam parte dessa coordenação, atividades de regularização fundiária, deixando clara a compreensão de que o direito à moradia requer suporte interdisciplinar, do qual o profissional do setor jurídico é imprescindível. Por outro lado, no referente aos projetos de habitação popular de mercado (HPM), verifica-se que o município busca garantir melhores condições de implantação para muitos empreendimentos em curso.

No caso do setor privado, envolvido com a produção habitacional através do PMCMV, cabe de início diferenciar os muitos agentes envolvidos presentes na RMF integrantes do setor da construção civil: proprietários fundiários, incorporadores, empresas de construção civil. Esses por sua vez mostram-se bastante heterogêneos na sua composição.

Referente aos proprietários fundiários, verifica-se historicamente na RMF a presença de crescente oligopólio, ampliando a concentração de terras e promovendo a segregação dos mais pobres em áreas cada vez mais periféricas. Aos proprietários de terras, vinculam-se construtores, responsáveis, muitas vezes, não apenas pela edificação das unidades, mas também pelo processo de incorporação dos terrenos e até pela sua comercialização. Esses construtores também atuam como promotores imobiliários mediante a aquisição de terrenos e posterior construção de UHs voltadas para famílias de renda média, configurando-se numa linha de atuação restritiva quanto ao público-alvo.

Contudo, desde as últimas décadas com a retomada da produção habitacional, verifica-se a ampliação do espectro de atuação dessas empresas, as quais passaram a atuar mediante os recursos disponibilizados por programas financiados pela CEF. Da mesma forma, a adoção de políticas habitacionais multiorientadas levou a que os serviços de urbanização de favelas e de provisão de moradia de interesse social viessem a ser alvos dessas empresas do setor da construção civil.

Vale aqui mencionar que o Programa de Arrendamento Residencial (PAR) constituiu-se 
num precursor daquilo que ocorreu nas primeiras fases do PMCMV. Por meio desse programa, algumas empresas do setor comandadas pelo Sinduscon-CE passaram a produzir UHs com recursos da $\mathrm{CEF}$, atendendo a um público-alvo com renda entre três e seis salários mínimos, sob a forma de pequenos condomínios fechados em bairros menos valorizados, em sua grande maioria situados em Fortaleza. Todos eles seguindo um mesmo projeto arquitetônico previamente aprovado.

No caso do PMCMV, verifica-se ao longo de sua recente execução, o destaque obtido pelo Sinduscon-CE, como instituição que passou novamente a articular junto à CEF maior celeridade na aprovação dos empreendimentos do programa. Como impacto dessas ações, definiu-se um projeto referência que agilizou a tramitação dos processos junto ao setor técnico da Caixa, ainda que em detrimento da qualidade urbanística e arquitetônica dos empreendimentos e especialmente na qualidade de vida dos seus moradores. Prevaleceu, no caso, a realização do sonho da casa própria, a qual levou à delegação de responsabilidades aos condôminos como o pagamento pela energia para iluminação dos espaços coletivos e castelos de água, segurança, limpeza dos espaços coletivos, saneamento básico mediante miniestações de tratamento de esgotos. No caso, a estratégia adotada, corresponde ao simples ajuste do projeto referência utilizado no PAR às normativas do PMCMV, induzindo ainda maior homogeneização dos projetos, mesmo que o público-alvo seja outro.

Vale mencionar que o PMCMV traz um novo elemento para as análises sobre a produção habitacional em termos de diversidade não apenas do público-alvo beneficiário, mas também como empresas que conseguem contratar empreendimentos (Cardoso, 2012). No caso da RMF, observa-se na primeira fase que não apenas as pequenas empresas que vinham atuando com recursos do PAR buscaram aprovar projetos. Empresas de maior porte, acostumadas à produção de residências para famílias de maior poder aquisitivo obtiveram êxito na contratação de empreendimentos nas faixas 2 e 3, denominadas habitação popular de mercado (Shimbo, 2012).

Outras empresas foram criadas mediante o estímulo do PMCMV através da transferência de capitais de outros setores produtivos, tendo em vista o lucro que o programa poderia garantir. Em função da oferta de recursos trazida pelo programa às grandes capitais do Nordeste, grandes empresas do setor da construção civil atuantes na produção habitacional passaram a expandir suas atividades. Com isso, intensificou-se processo migratório de empresas vindas do centro sul em busca de grandes contratos em função de uma demanda solvável presente, a qual, no caso de Fortaleza, superava a capacidade de resposta do setor da construção local (Rufino, 2012).

No entanto, em função das limitações no porte dos empreendimentos presentes na primeira fase do PMCMV, as empresas locais ainda mostraram capacidade de execução. Mesmo assim, algumas delas vieram a decretar falência após a entrega das unidades habitacionais (UHs), cujos moradores só não ficaram alijados de seus direitos por conta das garantias contratuais, havendo a contratação de empresas responsáveis pela manutenção dos mesmos. Noutros casos de falência das construtoras, em que os empreendimentos não estavam concluídos, houve a intervenção da CEF, contratando novas 
empresas, preferencialmente aquelas com experiência positiva no PMCMV. 0 caso dos empreendimentos denominados Escritores construídos em Fortaleza é exemplar, por se tratar de um conjunto de condomínios contíguos uns aos outros, cuja empresa entrou em processo falimentar. Após negociações com a CEF, algumas das primeiras empresas assumiram novos contratos, cada uma delas contemplada com um condomínio.

Todavia, na segunda fase, devido à possibilidade de aumentar o número de UHs até 5.000, passou a ocorrer um predomínio das grandes empresas do setor. Com isso ocorreu a chegada de empresas oriundas de outras capitais portadoras de procedimentos de gerenciamento da construção e know-how para empreendimentos de maior porte. Ainda nessa segunda fase, e seguindo os objetivos de celeridade e volume almejados pelo PMCMV, novos grandes conjuntos foram contratados, dessa feita com a inserção de grandes empresas que vêm a assumir grandes contratos. Mais ainda, observa-se a tendência de que as pequenas empresas da fase inicial do PMCMV passem a assumir empreendimentos de maior porte realizados no interior, resultado das ações do governo estadual visando disseminar o PMCMV junto aos centros regionais.

Sobre os beneficiários e as entidades vinculadas aos movimentos sociais de moradia é possível tecer algumas considerações. Tratando-se de um amplo programa habitacional reconhecidamente de interesse social, dado o objetivo de reduzir o déficit, era de se esperar que o programa viesse a promover processos de planejamento e discussões relacionados à questão da moradia. Todavia, quando se considera o papel da população beneficiária, verifica-se que a mesma se restringe à condição de receptora dos resultados, com limitado poder de interferência na qualidade em termos sociais, econômicos, culturais, arquitetônicos e urbanísticos.

Cadastrados pelos municípios e selecionados segundo critérios compartilhados entre as prefeituras e as normativas do PMCMV, as famílias receberam tratamento individualizado, salvo as situações em que o programa atende a demandas fechadas para reassentamentos por conta de intervenções urbanas. Reuniões de apresentação do PMCMV conduzidas pelos órgãos municipais responsáveis pelo cadastramento, assim como as visitas para confirmação de informações e as reuniões iniciais do trabaIho social se revelam como momentos participativos que antecedem a assinatura dos contratos.

Todavia, mesmo no caso da modalidade entidades do PMCMV passa a ocorrer a interferência direta do setor empresarial. Por um lado, o setor da construção civil incide no fomento à criação de entidades, forjando demandas sociais e tirando proveito de benefícios que o município possa oferecer dado o caráter social e participativo do PMCMV-Entidades. Por outro, apesar da cultura do mutirão em Fortaleza e da participação dos movimentos no processo decisório, há casos em que os construtores assumem o empreendimento como se esse fosse um outro qualquer, diferenciando das demais modalidades apenas com relação à identificação da demanda. Sob o risco de manipulações na criação de entidades, destaca-se a vulnerabilidade do PMCMV às práticas de coronelismo urbano. 


\section{Processos associados aos arranjos institucionais}

Nesta seção, almeja-se discutir as principais dinâmicas associadas aos arranjos institucionais, elencadas segundo a predominância dos agentes diretamente envolvidos e em função do uso de instrumentos de planejamento e gestão do solo urbano. Desde já destacamos que tal classificação corresponde a um recurso metodológico para a melhor compreensão dos processos, reconhecendo-se que para cada um deles é possível perceber protagonismos, interações e impactos, cujas intensidades revelam preponderâncias e submissões daqueles envolvidos com o PMCMV.

Um primeiro grupo de dinâmicas socioespaciais se refere às práticas do setor empresarial as quais revelam no curto prazo alterações na forma de atuação desse setor, bem como o seu poder de força junto ao Estado; em seguida tem-se um segundo agrupamento de dinâmicas que tratam das ações de instituições governamentais atreladas à operação e à implementação do PMCMV; por fim, busca-se reunir alguns processos associados aos instrumentos de planejamento urbano e habitacional e gestão do solo urbano.

As análises aqui realizadas estão embasadas no estudo de bases de dados obtidas junto à CEF correspondentes aos empreendimentos aprovados desde o lançamento do PMCMV até 31/12/2012. Esses dados indicam por empreendimento, o total de UHs, o valor do empreendimento, a empresa responsável, sua origem, a tipologia utilizada, a faixa e a modalidade do empreendimento, dentre outros. Para a sua realização, foram elaborados quadros que permitiram a totalização dos empreendimentos e a relativização da produção de empresas segundo as variáveis supracitadas.

\section{Ações do setor empresarial}

No que se refere às ações do setor empresarial foram identificados como principais processos: a) diversidade de empresas atuando no PMCMV diferenciadas quanto à origem, ao produto, à demanda, ao porte; b) continuidade das mesmas empresas construtoras do PAR desde o início do PMCMV nas diferentes faixas, utilizando tipologias $A \& U$ semelhantes; c) aumento da produção habitacional por meio de contratos de grandes empreendimentos HIS faixa 1 conduzidos por empresas de maior porte (local e nacional).

Diversidade de empresas atuando no PMCMV diferenciadas quanto à origem, ao produto, à demanda, ao porte

Considerando o quadro de empresas do setor da construção civil envolvidas com o PMCMV no Estado do Ceará, verifica-se que o mesmo obteve nos primeiros anos ampla dispersão, totalizando 59 empresas. Responsáveis pela contratação de 146 empreendimentos, observa-se que, em sua grande maioria, as empresas são locais, especialmente concentradas no atendimento à faixa 1 voltada para habitação de interesse social (HIS). Todavia, quando se analisa o número de contratos por empresa, verifica-se um processo de concentração em torno de 
algumas empresas. No caso, as construtoras Montenegro, Sumaré, Engeplan. Época, Fujita e Interpar se destacam com cinco ou mais conjuntos, totalizando 65 contratos, os quais equivalem a $42 \%$ do total assinado até o final de 2012.

Dessas empresas merecem ser destacadas: primeiro, a Época com 17 empreendimentos, totalizando $3.341 \mathrm{UHs}$. Sob a forma de pequenos condomínios justapostos e adotando como tipologia arquitetônica edifícios com dois pavimentos com apartamentos sobrepostos, a empresa abriu frentes nos municípios de Fortaleza e Caucaia, sendo a única a atuar nas três faixas de renda do PMCMV. Da mesma forma, chama atenção a atuação da Construtora Fujita, responsável por 5.920 unidades, das quais 5.536 apartamentos estão na faixa 1, em um único empreendimento com localização periférica denominado Cidade Jardim, o qual vem a inaugurar a nova fase do programa com a produção de grandes conjuntos de baixa altura e alta densidade.

Desse total de empresas, vale destacar a chegada de empresas oriundas de outros estados. De Pernambuco, duas empresas obtiveram contratos na faixa 1, e uma delas, a Constantini vem de Petrolina, assumindo um empreendimento com mais de 700 unidades em Juazeiro do Norte. De São Paulo, duas empresas têm contratos nas faixas 2 e 3, a Fibra e a Rossi respectivamente, as quais buscaram encontrar novos mercados. Além disso, constata-se que do total de empresas com contratos assinados até o final de 2012, vinte delas atuam apenas na faixa 1, cinco empresas (Época, Fujita, Sumaré, Abelardo Rocha e Montenegro) atuam nas faixas 1 e 2 e apenas uma (Época) tinha contratos nas três faixas. Destaca-se ainda que as empresas Damascena, Passaré e Messejana SPE contrataram empreendimentos nas faixas 2 e 3.

Entretanto, a presença de empreendimentos contratados como sociedades de propósito específico (SPE) corresponde a uma das mudanças reveladas nos primeiros anos do PMCMV. No caso, são 22 contratos, grande parte deles aberta pela empresa MRV consorciada com a local Magis. Juntas essas empresas tornaram-se responsáveis por mais de $11 \%$ do total contratado pelo programa, todos os empreendimentos nas faixas 2 e 3 . No caso, mais de $38 \%$ do que foi realizado na faixa 2 e mais de $52 \%$ do que foi produzido para a faixa 3. Outras empresas, ainda que venham de outros estados, como a Rodobens, ao chegar ao Ceará, abre nova razão social, seguindo a lógica das SPEs.

\section{Continuidade das mesmas empresas construtoras do PAR desde o início do PMCMV}

A RMF ao longo da primeira década do século XXI teve no PAR uma das formas de produção habitacional, o qual atendeu à demanda que não conseguia ter acesso à produção do mercado imobiliário formal e que não se enquadrava no público-alvo dos programas com projetos voltados para famílias de baixa renda realizados pelo Estado tidos como HIS.

Lançado ao final dos anos 1990, o PAR ao longo dos anos 2000 foi amplamente utilizado por construtoras locais, realizando empreendimentos de pequeno porte introduzindo em bairros periféricos e populares a produção imobiliária formal mediante a forma condomínio fechado. Dessa forma, o setor contribuiu com 
a exacerbação da fragmentação espacial, definindo setores com ampla presença de muros justapostos às áreas de ocupação, onde 0 acesso era dificultado seja pela largura das vias, seja pela definição de regras características da cidade informal.

Neste período que antecede o lançamento do PMCMV, foram construídos 91 empreendimentos pelo PAR, totalizando 11.266 UHs. Em média, cada condomínio tem 124 moradias, representando o porte de muitos dos conjuntos que viriam a ser produzidos pelo PMCMV na sua primeira fase.

Quatro empresas se destacaram na produção habitacional pelo PAR com mais de 1.000 unidades em pelo menos seis empreendimentos: Época Engenharia; CRD, Engeplan e Montenegro. Somadas à Construtora Sumaré, à ECB Engenharia Comércio Bezerra Ltda. e à Fujita Engenharia, essas correspondem ao grupo de construtoras que atuaram tanto no PAR como no PMCMV. Juntas, essas empresas são responsáveis por mais de $53 \%$ do total de empreendimentos, os quais englobam quase dois terços do total de unidades produzidas pelo programa na RMF.

Sob o comando do Sinduscon-CE, essas empresas construíram empreendimentos residenciais, disseminando-se pelo município de Fortaleza em pequenos recortes de tecido urbano, agrupando-se prioritariamente em alguns bairros de Fortaleza. Do total de 91 empreendimentos, 90 encontram-se na RMF. No caso da RMF, vale mencionar que algumas dessas empresas prosseguiram no atendimento à demanda por habitação popular de mercado (HPM). Entretanto, a maior parte dos novos empreendimentos se volta para a habitação de interesse social na faixa 1 do
PMCMV, trazendo para essas empresas um novo tipo social de usuário.

Na primeira fase do PMCMV, a Época Engenharia merece destaque com a assinatura de 18 contratos (3.341 UHs) em Fortaleza e Caucaia, dos quais 14 voltados para a faixa 1. Situados em bairros periféricos e precários em termos de infraestrutura, esses empreendimentos seguiram a forma adotada pelo PAR, no caso condomínios com prédios de apartamentos sobrepostos, assim como a justaposição de condomínios, cujos muros passam a interferir fortemente na paisagem. Observa-se que apesar de o programa, na sua primeira fase, limitar os contratos a 500 unidades, o que inclusive permitiria a implantação de conjuntos de pequeno porte pelos mais diversos bairros da cidade, a estratégia adotada por essa empresa finda por reconduzir aos flancos periurbanos os beneficiários do PMCMV, favorecendo com isso 0 aumento da segregação residencial. Por sua vez, ao final da segunda fase, a empresa Fujita Engenharia, que havia realizado apenas um empreendimento pelo PAR, passa a predominar na produção HIS, com a contratação do primeiro grande conjunto do PMCMV da RMF com 5.536 unidades habitacionais agrupadas num mesmo setor da cidade.

Essa nova forma de produção por meio de grandes conjuntos, ao requerer maior experiência das empresas de modo a evitar os riscos da suspensão dos contratos e da não conclusão dos imóveis, tende a promover a oligopolização da produção habitacional, visto que as pequenas empresas locais que vinham se inserindo nesse ramo tendem a passar por dificuldades em demonstrar sua viabilidade econômico-financeira para a realização de conjuntos de maior porte. 
Aumento da produção HIS

via contratação de grandes

empreendimentos

Passado o seu lançamento em 2009, o PMCMV no Ceará só veio a ter grandes contratos assinados em fins de 2012. Num total de 153 empreendimentos realizados para todo o estado, viabilizou-se a construção de $37.768 \mathrm{UHs}$, as quais ainda se mantiveram abaixo da meta estadual pretendida na primeira fase do programa. Desses, cerca de 10.429 UHs correspondiam a nove empreendimentos contratados em 2012, representando mais de $27 \%$ do total e sinalizando mudanças trazidas na segunda fase do PMCMV.

Chama atenção que 5.536 apartamentos tenham sido contratados junto à Construtora Fujita S/A por meio de cinco empreendimentos justapostos, utilizando a mesma estratégia da primeira fase por empresas em construir condomínios vizinhos. Da mesma forma, outros dois empreendimentos com 2.084 UHs no total foram contratados em Sobral, a serem construídos pela empresa Direcional num mesmo setor da cidade em áreas contíguas. A mesma empresa também consegue emplacar um novo contrato na RMF, no caso dos municípios de Maracanaú, às margens do $4^{\circ}$ Anel Viário, onde outras 2.096 residências entraram em construção. Um outro empreendimento realizado pela empresa pernambucana Constantini em Juazeiro do Norte, $3^{\circ}$ maior município do Ceará completa esse quadro. Esse representa mais de $35 \%$ do total construído pelo PMCMV faixa 1 naquele município.

0 que esses números revelam? Primeiro, a mudança no porte dos empreendimentos, sinalizando que uma forma de produção mais intensa tende a predominar, favorecendo as maiores construtoras. Segundo, observa-se que grandes empreendimentos requerem amplas superfícies, as quais só são obtidas em terrenos periféricos, e que por serem mais baratos, ampliam a margem de lucro dos construtores e incorporadores.

A opção por grandes empreendimentos leva ainda a que municípios metropolitanos venham a ser priorizados por grandes empresas, restando os demais centros regionais distantes da RMF para as menores que tendem a abrir novas frentes. Além disso, diante do amplo déficit a ser atendido na RMF, o mercado torna-se mais favorável às grandes empresas com maior experiência no setor HIS e com capacidade de gerenciamento da construção.

No caso da RMF, é possível reconhecer disputas entre as duas maiores: a local Fujita S.A. e a mineira Direcional. A primeira, empresa cujo empreendimento encontra-se em andamento, qualifica-se para novos contratos, como um primeiro MCMV na modalidade entidades com mais de 3.000 unidades. A segunda, empresa que tem atuado em outros estados do Brasil, já é considerada a $12^{\mathrm{a}}$ maior empresa do setor com receita bruta de mais de $1.4 \mathrm{bi}$ Ihão de reais e mais de 14.500 empregados. De acordo com base de dados fornecida pelo MCidades/CEF, a Direcional ao final de 2013 já tinha contratos na Faixa 1 do PMCMV que beiravam 40.000 unidades habitacionais distribuídos em oito estados brasileiros contratados majoritariamente em 2012. Dessa mesma empresa, já se encontram em construção em Fortaleza e Maracanaú novos grandes conjuntos os quais apresentam proximidade na sua localização periférica antevendo-se problemas no acesso às infraestruturas e aos serviços 
revelando-se em possíveis casos de negação do direito à cidade.

\section{Ações dos governos estadual e municipais}

Para compreender a atual situação dos arranjos institucionais relacionados ao PMCMV na RMF, é imprescindível a análise dos mesmos em outras escalas. No caso desse artigo, o olhar se volta para o estado do Ceará sinalizando os motivos de sua concentração na região metropolitana bem como para a região Nordeste investigando as dificuldades encontradas para a sua disseminação nos demais municípios enquadrados para obras do PMCMV.

Dentre as dinâmicas identificadas ao longo desta pesquisa, merecem ser destacadas: a) obras do PAC urbanização de favela associadas às áreas de risco e à mobilidade concentram interesses dos governos estadual e municipal na primeira fase do PMCMV; b) dificuldades na expansão do PMCMV junto aos centros regionais levando a que o Governo promova medidas dinamizadoras; c) contratação de empreendimentos de grande porte para municípios/centros regionais na faixa 1, posteriores a outros contratados das faixas 2 e 3 .

\section{Obras do PAC assentamentos precários concentram interesses dos governos na $1{ }^{\text {a }}$ fase do PMCMV}

Desde o início do século XXI, o governo estadual do Ceará teve a diminuição de sua máquina administrativa, delegando responsabilidades de políticas públicas aos municípios.
No caso do desenvolvimento urbano e da habitação, houve a extinção da Superintendência de Desenvolvimento Urbano (Sedurb) e da Companhia Estadual de Habitação (Cohab-CE), reduzindo-se as ações governamentais em ambas as frentes.

Todavia, desde a criação do Ministério das Cidades, quando foram ampliados os recursos voltados para a produção habitacional e o planejamento urbano, o governo estadual buscou promover ações, incrementando sua capacidade de gestão. Todavia, permaneceu seguindo a prática de privilegiar o projeto em detrimento do processo de planejamento e desconsiderando a necessária associação das políticas urbana e habitacional.

Fortaleza, por sua vez, detentora de números alarmantes no que se refere à problemática da moradia, passa lentamente a assumir o seu papel, acelerando o processo com oportunidades trazidas com os recursos de programas criados nos primeiros anos do governo Lula ou mesmo de outros como o Programa Habitar Brasil BID que até então não vinha sendo implementado na sua componente de desenvolvimento institucional.

Some-se a isso a aproximação entre as gestões estadual e municipal nos primeiros anos do Ministério da Cidade, integrando seus objetivos e compatibilizando suas ações no campo da política urbana e habitacional, ambas priorizando projetos de intervenções vinculados à mobilidade e à remoção de áreas de risco.

Sem que se tenha um processo de planejamento que articulasse as políticas urbana e habitacional, os projetos e as respectivas obras assumiram caráter pontual, sugerindo discrepâncias entre os mesmos quanto ao 
porte e à forma de intervenção. Além disso, vale destacar a presença das gerenciadoras e a terceirização de boa parte dos serviços, levando a que as instituições públicas não consigam construir um modus operandi para novos projetos. Atribuições como o trabalho social ao serem repassadas às consultorias externas agravaram ainda mais a situação, levando por vezes a população atingida à situação de insegurança e desamparo.

Nesse sentido, desde que o PMCMV foi lançado, os governos estadual e municipal, apesar de apoiarem a sua implementação, tiveram a maior parte de seus esforços concentrada em projetos habitacionais vinculados à urbanização de favelas em situação de risco, assim como de provisão habitacional para famílias removidas por obras de mobilidade urbana.

No caso do governo estadual, seus olhos se voltavam para os chamados projetos especiais: Projeto Maranguapinho e Cocó que visam, além da intervenção em áreas de risco e o reassentamento em grandes conjuntos periféricos, construir obras de drenagem e contenção de enchentes; o projeto Dendê, atendendo à comunidade próxima ao Centro de Feiras e Eventos construído pelo governo estadual, visando o desadensamento da área e a sua urbanização, mediante o reassentamento de famílias nas proximidades, de modo a requalificar o seu entorno cujos terrenos vazios aguardam melhorias na área para que possam vir a ser incorporados pelo mercado imobiliário. Tudo isso faz com que nos primeiros anos o governo estadual tenha uma ação mais tímida em relação ao PMCMV, visto que dispunha de verbas garantidas para a execução dessas obras.

No caso de Fortaleza, a situação é similar. Desde o momento do lançamento do PMCMV, a Habitafor conduz o cadastro de famílias, atingindo em poucos dias mais de 120 mil famílias. Tamanho desafio requereria a participação de outros agentes, como o setor da construção civil, o qual, além de mostrar-se reticente, fez a rápida leitura de que o PMCMV demandaria sua maior articulação com a CEF. Da parte do município, aguardavam-se medidas relacionadas à política fundiária, facilitando a obtenção de terrenos. Entretanto, dada a necessidade da presença de infraestrutura nesses terrenos, a situação tornou-se mais difícil, quase inviável.

Diante dos movimentos sociais fragilizados e em processo de reorganização, dado que algumas antigas lideranças e seus articuladores passaram a compor os quadros do governo municipal, o município remanesce com as ações já contratadas, reproduzindo o mesmo processo de atuação do governo estadual sem promover avanços em busca de projetos autogestionários. No caso, o projeto Vila do Mar, iniciado ainda nos anos 1990 como Costa Oeste sob a gestão do governo estadual, considerava a remoção de milhares de famílias de ocupações à beira mar, no front oeste de Fortaleza, e seu reassentamento em áreas distantes, havendo ainda a opção pela indenização. Posteriormente passou para a Prefeitura de Fortaleza em 2005, quando a mesma redefiniu os caminhos do mesmo, modificando suas diretrizes em termos de reassentamento das famílias. Contando com recursos do PAC Urbanização de Favelas, o projeto assume caráter especial, tornando-se um dos ícones da gestão. Sem que estivesse associado a qualquer secretaria, 0 projeto é exemplar no sentido de que sua gestora mencionava ter status de secretária.

Ao mesmo tempo, muitos projetos de urbanização de favelas foram iniciados pela 
Habitafor, os quais trouxeram em seu conteúdo a provisão habitacional como estratégia de intervenção, dado que as áreas selecionadas estavam em situação de risco. Com isso, verifica-se um amplo processo de remoção de comunidades marcado pela dicotomia no processo de reassentamento: por um lado, para pequenos conjuntos próximos; por outro, para conjuntos de maior porte em áreas distantes.

Situações díspares como os projetos Maria Tomásia e Papicu podem exemplificar a dualidade das ações dessa fundação. No primeiro, teve-se a construção de 1.200 unidades habitacionais destinadas ao reassentamento distante de famílias removidas de áreas de risco em bairros de renda média alta, num setor com sérios problemas de inserção urbana. Por conta disso, o projeto enfrentou queixas dos seus moradores desde o início, com muitos casos de desistência e abandono dos imóveis. No segundo, optou-se pelo reassentamento nas proximidades. Próximo a um grande shopping recentemente concluído, as famílias foram parcialmente reassentadas em conjunto habitacional implantado em terreno vizinho mediante recursos do governo federal e de operação urbana consorciada. Longe de considerar as estratégias distintas como resultado de uma política multiorientada, essa dicotomia retrata a sua indefinição dada a falta de princípios e critérios pré-definidos.

Apesar da diversidade de programas governamentais, dos quais os recursos foram obtidos, observa-se a adoção de um mesmo tipo habitacional. Ainda que paralelamente tenha sido conduzido processo de planejamento para elaboração de política habitacional e posteriormente de plano local de habitação de interesse social, verifica-se que nenhum dos dois foi implementado. Somado às condições precárias de funcionamento do conselho municipal de habitação, a instituição perde força junto aos movimentos sociais, especialmente os novos oriundos de manifestações contrárias à copa.

Com isso, desde o início da nova gestão, a Prefeitura de Fortaleza passou a apostar no PMCMV como fonte de recursos para implementação de suas metas e promessas de campanha, mediante a contratação de grandes conjuntos com recursos do FAR, via CEF e Banco do Brasil, inclusive contando com o apoio do governo estadual, visto que os mesmos retomaram as suas parcerias.

\section{Problemas na expansão do PMCMV junto aos centros regionais}

Desde que o PMCMV foi lançado, o estado do Ceará tem enfrentado dificuldades na disseminação do programa, considerando os centros regionais e os demais municípios enquadrados para realizar contratos nas modalidades atendidas com recursos do FAR, ou mesmo, com recursos aprovados pelo CCFGTS. Na primeira fase, apenas 11 dos 42 municípios enquadrados conseguiram obter êxito na contratação, incluindo-se tanto os metropolitanos como aqueles com população acima de 50 mil habitantes. Por outro lado, percebe-se a ampla dispersão do programa MCMV na sua componente Oferta Pública de Recursos atendendo a quase a totalidade dos municípios do Estado com contratos de 30 e 60 UHs operacionalizados por bancos privados sem sede no Ceará.

Isso levou o governo estadual através da Secretaria das Cidades a estabelecer algumas medidas, considerando o déficit estadual, 
a disponibilidade de recursos e a representatividade política que as obras trazidas pelo PMCMV poderiam trazer. Vale lembrar que 0 atual governador era secretário das Cidades, e como candidato ao governo do estado, na época, teve todo o interesse na contratação de novos empreendimentos pelo interior do Ceará.

Dentre as fatores causais para as dificuldades de contratação nos centros regionais levantados junto aos agentes envolvidos podem ser mencionados: as más condições de infraestrutura urbana nos municípios impedindo a aprovação dos contratos junto à CEF; o desinteresse do setor da construção civil local dadas as dificuldades encontradas na realização dos projetos mesmo na RMF; as condições precárias da mão de obra local; a indisponibilidade dos municípios na concessão de terras para HIS, ainda que grande maioria tenha revisto seus planos considerando o Estatuto da Cidade.

Relato do Coordenador de Habitação da Secretaria das Cidades apontou como medidas adotadas: a) a criação de comitê para que os agentes envolvidos viessem à concertação de suas demandas quanto às infraestruturas; b) a definição por parte das prefeituras de terrenos para os conjuntos; c) a complementação de recursos em $8.000,00$ reais por $\mathrm{UH}$ creditado pelo governo do estado como contrapartida para os novos contratos. Tudo isso para motivar o setor da construção civil a empreender esforços e abrir frentes de trabalho nesses municípios.

Todavia, ao final da segunda fase, apenas 16 municípios, incluídos os da primeira fase, conseguiram aprovação de contratos com recursos do FAR e do CCFGTS, apesar dos esforços governamentais, e os novos integrantes eram da RMF. Desses, destaque para o município de Eusébio, onde o único empreendimento contratado era para a faixa 2 com recursos do CCFGTS, confirmando a tendência de que esse município seja opção para investimentos do mercado imobiliário formal. Posteriormente, a Secretaria das Cidades passou a divulgar que novos empreendimentos estavam em estágio avançado com vistas à sua contratação. Os impedimentos continuavam os mesmos como os problemas fundiários dos terrenos escolhidos e a falta de infraestrutura urbana. Contudo, segundo uma nova base de dados fornecida ao final de 2013 pelo Ministério das Cidades, esses novos contratos teriam sido realizados para as faixas 2 e 3 com recursos CCFGTS e de porte bem menor, grande parte deles com menos de 10 unidades, o que nos leva a crer que se tratem de empreendimentos contratados por construtores na condição de Pessoa Física.

\section{Dificuldades na contratação de conjuntos para centros regionais na faixa 1}

Em viagens de campo realizadas aos municípios do interior, obteve-se a informação da possível contratação de novos empreendimentos pela faixa 1 do PMCMV para alguns dos municípios enquadrados. Por meio dessas viagens, alguns relatos são recorrentes como: a realização de reuniões públicas com o Secretário das Cidades divulgando o programa e indicando a localização e disponibilidade de terreno; a realização de cadastro de famílias para posterior seleção; a definição da empresa e mesmo a apresentação do projeto.

Confirmados por notícias da mídia local, algumas características comuns a esses 
municípios e seus respectivos contratos podem ser apontados: o porte do empreendimento na ordem de 500 unidades; a localização periurbana, via de regra diametralmente oposta às frentes de expansão do mercado imobiliário e dos empreendimentos das faixas 2 e 3; a sinalização de uma segunda etapa do empreendimento no curto prazo; a realização por empresa com experiência nesse ramo de serviço, tendo Fortaleza como sede; a proximidade do empreendimento do PMCMV em relação ao setor industrial; a unicidade do projeto e a adoção de casa térrea unifamiliar como tipo habitacional.

Situação exemplar pode ser obtida em Russas onde a localização de conjunto habitacional com 500 UHs ocorre em terreno vizinho à indústria de calçados Dakota, numa das saídas da cidade. Apesar de amplos terrenos vazios nos interstícios entre a periferia e os bairros intermediários e pericentrais, a opção dessa localização evidencia problemas de inserção urbana para o futuro próximo. No mesmo município, tem-se a construção de alguns empreendimentos por meio do PMCMV para as faixas 2 e 3 em terrenos de pequeno porte, atendendo à demanda com maior capacidade de pagamento em terrenos melhor localizados. Disso observa-se que mesmo para um centro regional com população de 30 mil habitantes na zona urbana, o programa ao desconsiderar os instrumentos da política urbana pode vir a induzir a especulação imobiliária e a segregação residencial.

Situações como essas indicam a necessidade de uma abordagem intersetorial na implementação desse programa, considerando que o porte dos empreendimentos requer equipamentos sociais, condições de circulação e meios de transporte, assim como redes de abastecimento de água e de saneamento.

Ao atender às pressões pela construção de empreendimentos maiores e concentrados num só terreno, ao priorizar o baixo custo do terreno como critério para a sua compra, tem-se como consequência o crescimento desordenado e disperso. Com isso, favorecem-se os proprietários de terras em setores intermediários entre o centro e a periferia, cujas glebas vazias passam a ser valorizadas em detrimento da perda de qualidade de vida dos futuros moradores e mesmo do abandono dessas unidades pela ausência de cidade no seu entorno.

A questão trazida à tona com as dificuldades de implantação de empreendimentos voltados para famílias na faixa de interesse social evidencia problemas associados à dissociação entre as políticas urbana e habitacional, assim como a ineficácia dos instrumentos até aqui elaborados como os planos diretores municipais e os planos locais de habitação de interesse social.

\section{Aplicabilidade dos instrumentos de planejamento urbano e habitacional}

No que se refere à aplicabilidade dos instrumentos de planejamento e gestão do solo urbano associados à implementação do PMCMV, destacam-se as seguintes dinâmicas: a) a baixa efetividade da legislação urbanística municipal na definição das áreas para os PMCMV, inexistindo casos de utilização do Estatuto da Cidade; b) a ausência de articulação entre os planos diretores municipais e problemas na implantação de conjuntos periféricos evidenciando 
a necessidade de planos de expansão urbana e habitacional metropolitano; c) o reconhecimento de problemas recorrentes na realização do trabalho social influenciam negativamente a organização dos grupos atendidos e a apropriação dos equipamentos de uso coletivos pelos moradores.

\section{Baixa efetividade da legislação urbanística na definição das áreas para os PMCMV}

Ao analisarmos as áreas onde os empreendimentos habitacionais do PMCMV estão sendo inseridos, observa-se que as mesmas não levaram em consideração os conteúdos dos planos diretores municipais, no que se refere aos instrumentos do Estatuto da Cidade, os quais poderiam facilitar a aquisição de terrenos meIhor localizados e dotados de infraestrutura e serviços urbanos.

Fortalecendo a hipótese da total dissociação entre as políticas urbana e habitacional, assim como a constatação de que a definição das áreas decorre da decisão dos construtores e da aceitação das demais instituições de financiamento, os casos estudados ilustram essa situação. Prevalecem critérios como o custo do terreno, fundamental para o construtor. Mesmo a disponibilidade de infraestrutura e serviços, apesar de serem mencionados como disponíveis no entorno, derivam em problemas para os moradores, visto que nem sempre estavam em condições de uso.

Além disso, compreende-se que desde o preenchimento da FIT (Ficha de Informações sobre o Terreno) e da FRE (Fichas Resumo dos Empreendimentos) que em nenhum momento a pertinência da localização dos mesmos diante do conteúdo da política urbana e mesmo da lei de uso e ocupação do solo é questionada. Sobre a localização do empreendimento, as opções são: inserido na malha urbana, periferia e área de transição urbano rural, onde uma não exclui a outra. No que se refere ao uso predominante: residencial uni ou multifamiliar, comercial, industrial, misto, as opções mostram-se presas a um modelo de zoneamento funcionalista que não retrata a realidade das cidades brasileiras. Quanto à densidade de ocupação, entre alta, normal ou baixa, faltam maiores elementos para definir 0 que essa classificação significaria, além de diferenciar a densidade quanto à região e quanto à localização na cidade. Por fim, no que diz respeito à disponibilidade de transporte faltam elementos para justificar o que seria bom, regular ou insuficiente.

Em nenhum dos casos estudados, foi mencionado nas entrevistas o uso de qualquer instrumento do estatuto da cidade, como as Zeis vazias, que apesar de disponíveis na legislação urbana da maior parte dos municípios não foram utilizadas. Em Fortaleza, o Plano Diretor Participativo de 2009 reúne mais de 60 áreas consideradas como Zeis vazias, sem que nenhuma tenha sido alvo de projeto (Ancona, 2009; Rolnik, 2010).

Nos casos analisados para Fortaleza, os empreendimentos aprovados pelo FAR na $1^{\text {a }}$ fase se localizam nas Zonas de Requalificação Urbana I e II (ZRU), marcadas pela precariedade das infraestruturas, pela presença de áreas de ocupação e loteamentos irregulares. Fossem considerados os conteúdos e as recomendações da legislação, esses seriam construídos apenas em setores dotados de infraestrutura 
e serviços urbanos, e, por conseguinte, aptos aos novos empreendimentos.

Com vistas à terceira fase do PMCMV e buscando cumprir as promessas de campanha, a PMF partiu para a aprovação de grandes conjuntos num setor da cidade considerado como Zona de Ocupação Restrita (ZOR), onde as recomendações são contrárias ao tipo de empreendimento. Controlar e inibir a ocupação dessas áreas devido às condições esparsas de ocupação e às carências de infraestrutura e serviços, apesar de apontadas no plano diretor, não conseguem impedir a aprovação desses novos grandes conjuntos.

Mesmo para os casos de Maracanaú e Caucaia, os problemas se repetem com outros elementos. Em Maracanaú, os conjuntos produzidos com recursos do FAR encontram-se em áreas descontínuas, distantes da centralidade principal do município, em zonas com maior fragilidade ambiental. Sua localização em terrenos distantes e próximos ao eixo transversal ao município vindo de Fortaleza em direção à Maranguape contribui para o crescimento desordenado do município. Por sua vez, em Caucaia, alguns dos empreendimentos aprovados desconsideram as recomendações do plano, que demonstram seu viés segregacionista, tornando proibitivo o uso com fins HIS para alguns setores, assim como estabelecendo lotes mínimos de 250 metros quadrados.

\section{Ausência de articulação entre os PDs municipais e necessidade de planos de expansão urbana metropolitano}

Desde a elaboração dos planos diretores municipais, uma das questões levantadas por ocasião dos debates em Fortaleza dizia respeito à ausência da questão metropolitana nos seus conteúdos. Disso decorre uma série de conflitos de uso do solo e incompatibilidades de ocupação do território. Sem pretender esgotar a lista de problemas, podem ser aqui citados: zonas de litígio em que os limites municipais não são reconhecidos; loteamentos aprovados em municípios vizinhos, às vezes parcialmente, propiciando situações de irregularidade fundiária e insegurança na posse por seus moradores; produção de loteamentos clandestinos, os quais remanescem sem controle urbano; descontinuidades viárias, influenciando negativamente a implementação de redes de infraestrutura urbana; transposição de demandas sociais relacionadas à maior proximidade das periferias nas zonas conurbadas de núcleos e centralidades urbanas de municípios vizinhos; avanço das áreas de risco no contra-fluxo dos rios urbanos desde Fortaleza em direção aos municípios à montante; degradação dos recursos naturais vinculada à falta de infraestrutura e de serviços urbanos; dificuldades no acesso aos equipamentos sociais, via de regra vinculado ao domicílio; custo excessivo dos transportes coletivos para um grupo cada vez maior de pessoas que comutam de um município ao outro, na ausência de um processo de planejamento metropolitano.

Vale destacar que se entende como processo de planejamento territorial metropolitano não apenas a formulação de um plano, mas a definição de papéis e responsabilidades, assim como da sua institucionalização, implementação e operacionalização, sem os quais, estar-se-ia tão somente produzindo relatórios e normativas fadadas às gavetas e prateleiras. 
Na ausência desse processo, desde o lançamento do PMCMV, os grandes vazios urbanos de Maracanaú e Caucaia tornaram-se alvo de projetos, dado o menor custo da terra urbana (sem infraestrutura), vindo a contribuir com a consolidação da conurbação entre eles e Fortaleza em duas direções: sudoeste e oeste respectivamente. Nessas bordas, inicia-se a implantação de pequenos empreendimentos isolados sob a forma de condomínios horizontais, os quais passam a ter seu entorno complementado por empreendimentos contíguos, decorrendo num território fragmentado e descontínuo, onde os espaços extramuros denunciam a necessidade de um plano urbanístico.

Além disso, o setor sudoeste de Fortaleza, conhecido como Grande Bom Jardim torna-se alvo de projetos de reassentamento habitacional de famílias removidas de áreas de risco integrantes do Projeto Maranguapinho com recursos do PAC, os quais contemplam: a urbanização das áreas de risco, recuperadas como espaços livres para a cidade; as obras de infraestrutura; a provisão habitacional somada a pequenos equipamentos coletivos.

Complementa a problematização em torno desta dinâmica socioespacial, a compreensão de que as demandas de Fortaleza tendem a migrar para os municípios vizinhos, especialmente nas faixas 2 e 3 que inclusive podem vir a pressionar os empreendimentos da faixa 1. Isso decorre dentre outros fatores: da pequena oferta adiante da demanda reprimida; da informalidade na aquisição do imóvel como marca de um setor onde não existe controle urbano; da produção em quantidade nos municípios vizinhos e a oferta atendendo a cadastros municipais, onde na ausência de um efetivo e eficaz trabalho social, o bem imóvel amplamente subsidiado não tem o seu real valor reconhecido; da presença de muitos problemas derivados das más condições de inserção urbana induzindo famílias a buscar outras formas de moradia, levando-as ao abandono e à venda dos imóveis.

Disso vem à tona a necessidade de processo de planejamento metropolitano voltado para estabelecer mecanismos de articulação entre os planos municipais quanto às frentes de expansão dos municípios, assim como para definir em conjunto o uso de instrumentos que garantam de forma consorciada a urbanização e a posterior disponibilidade de terra urbanizada para novos empreendimentos, evitando-se o agravamento dos problemas aqui apresentados (Santoro, 2012).

\section{Problemas recorrentes na realização do trabalho social}

Os problemas associados à redução do papel do Estado tornam-se mais evidentes quando se investigam os impactos do trabalho social junto aos beneficiários, o qual, em seus objetivos específicos, visa contribuir com a organização das famílias beneficiadas. Vale destacar que esse corresponde a um dos poucos processos em que se pode investigar a forma como se dá a interação entre o poder local e a população, evidenciando-se a necessidade de maior detalhamento do programa no nível local referente aos procedimentos para definição das famílias beneficiadas.

Considerando a necessária abordagem intersetorial que o enfrentamento da questão da moradia requer, deve ser mencionado que o trabalho social tem limitações diante 
dos problemas a serem enfrentados, os quais muitas vezes advêm das más condições de localização, da forma como se deu a produção habitacional, assim como em decorrência das disparidades de poder entre os agentes envolvidos na tomada de decisão.

De qualquer maneira, o trabalho social no PMCMV acaba por se constituir no único e derradeiro momento de interação entre o município e os beneficiados, ganhando com isso maior importância, no sentido que se coloca como esclarecedor das condições em que os imóveis são entregues e como facilitador do processo de organização comunitária.

Tendo em vista a vida em condomínio que a tipologia urbanística e arquitetônica predominantemente é adotada no PMCMV na RMF, o trabalho social ganha ainda maior importância pelo fato de incluir no orçamento das famílias novas, despesas com taxas de condomínio às quais elas não estão habituadas, assim como a necessidade de compartiIhar responsabilidades. 0 problema se agrava, se considerarmos a amplitude do espectro de renda na faixa 1, variando de famílias com renda inferior a 1 salário mínimo oriundas de áreas de ocupação a famílias com renda de $1.600,00$ reais provenientes de casas em que pagavam aluguel.

De acordo com as entrevistas realizadas com moradores dos conjuntos já habitados, constatou-se que o contato dos moradores com os técnicos de trabalho social é bastante reduzido e descontínuo. A metade dos entrevistados mencionou ter tido contato antes da mudança, um quarto dos moradores apenas após a mudança, e o restante informou que nunca teve contato com os técnicos.
Quanto ao tipo de atividade realizada pelo técnico de trabalho social ocorrido por ocasião do contato com os moradores, observa-se que o foco esteve concentrado na mudança e na organização do condomínio, conforme afirmaram mais de 2/3 dos moradores. Questões vinculadas às condições de inserção urbana, como a proximidade de equipamentos sociais e sua apropriação pelos beneficiários foram mencionadas por menos de $17 \%$ do total dos entrevistados; da mesma forma, pouco mais de $20 \%$ disseram ter havido encaminhamentos e discussões associadas à realização de cursos profissionalizantes. Dada a importância desses pontos para a melhoria nas condições de vida e para a permanência das famílias nos condomínios, recomenda-se que esses pontos sejam melhor explorados nas atividades do trabalho social.

Decorrem da fragilidade da realização do trabalho social, problemas como a inadimplência no pagamento das taxas e a desorganização afetando diretamente a gestão dos condomínios associada à participação das famílias nas reuniões. Além disso, a presença recorrente de uso misto, repasse a familiares, venda, aluguel, invasão e desocupação: situações pontuais que somadas indicam problemas desde a formulação do cadastro até a seleção de beneficiários.

\section{Considerações finais}

Neste artigo, buscou-se apontar e discutir um quadro de dinâmicas vinculadas às condições em que se encontram os arranjos institucionais vinculados ao PMCMV na RMF. Essas 
foram classificadas quanto às ações dos setores imobiliário e da construção civil; quanto às práticas do Estado considerando as diferentes esferas de governo; quanto à associação entre os instrumentos de planejamento urbano e habitacional. Apesar de terem a RMF como foco, fez-se necessário a realização de abordagem pluri-escalar, incluindo a região Nordeste, subdivida em estados; o estado do Ceará em seus municípios diferenciados pelo porte de sua população; a própria RMF da qual foram selecionados os municípios com maior produção habitacional atrelada ao programa.

No caso, Fortaleza como o mais populoso revelou dificuldades vinculadas à especulação imobiliária comandada pelo setor da incorporação e da construção civil. Além disso, percebeu-se num primeiro momento, a continuidade das empresas de pequeno e médio porte que atuavam através do PAR, as quais passaram a ter contratos no PMCMV. Ainda que diversificadas, com o passar do tempo denotou-se a concentração em torno de poucas empresas em termos de quantidade de unidades habitacionais. Diante destas dificuldades, o PMCMV passa a ser mais efetivo nos municípios vizinhos a Fortaleza: Caucaia ao oeste e Maracanaú ao sudoeste, onde as facilidades para obtenção de terrenos e a disponibilidade de demanda viabilizaram lucros no curto prazo. Além disso, tratando-se de empreendimentos de pequeno porte, as mesmas empresas que vinham atuando na provisão habitacional pelo PAR sob o comando do Sinduscon obtiveram êxito na efetivação de contratos.

Todavia, mais recentemente configura-se a tendência de oligopolização do programa por meio de grandes empresas dotadas de capital, experiência e pacote tecnológico para enfrentar a produção de grandes conjuntos periféricos. Tende a restar às demais a busca por novos empreendimentos em centros regionais do estado, tão logo a terceira fase do PMCMV venha a ser dotada de recursos.

Cumpre destacar que o PMCMV ao disponibilizar amplos recursos para a contratação de empreendimentos residenciais, atendendo a diferentes faixas de renda, a serem realizados pelo setor da construção civil, pôs em cheque os instrumentos da política urbana formulados nos últimos anos. Da mesma forma, no nível local colocou numa mesma arena os diferentes agentes sociais, em que num cenário otimista poderiam ser pactuadas medidas que favorecessem a todos, ou num cenário pessimista, as disputas poderiam vir a se acirrar refletindo no aumento das disparidades socioespaciais (Maricato, 2011).

Para tanto, a RMF, historicamente marcada por suas desigualdades sociais traduzidas nas condições precárias de moradia para muitos e no privilégio com que poucos desfrutam dos benefícios da urbanização, representou um recorte espacial exemplar e dos mais férteis.

A concentração do desenvolvimento urbano no município-polo, para onde convergem a maior parte dos investimentos, a criação de instituições públicas municipais voltadas para o enfrentamento do problema habitacional na última década, as tentativas do governo estadual de retomar ações na produção habitacional, as dificuldades vivenciadas nos processos de planejamento urbano na esfera municipal, a força dos oligopólios que comandam o setor imobiliário e as más condições de distribuição das redes de infraestrutura, para citar apenas 
algumas, são características cuja simultaneidade e sobreposição na RMF reforçam sua condição especial como objeto de estudo.

Diante do quadro de problemas relacionados às dinâmicas que retratam a situação dos arranjos institucionais, pretende-se aqui sugerir algumas diretrizes visando contribuir com a melhoria do PMCMV. Primeiramente, recomenda-se o redesenho das atribuições dos agentes envolvidos no programa, especialmente em relação àqueles que fazem parte do quadro funcional dos municípios, cuja ausência dos processos decisórios deriva em grande parte dos problemas detectados.

Em seguida, tendo em vista a aprovação de conjuntos habitacionais de grande porte, torna-se imprescindível a associação entre as políticas urbana e habitacional - nas suas diretrizes e nos seus instrumentos - bem como às demais políticas setoriais envolvidas com a expansão urbana de modo a amenizar os impactos sobre os moradores e a mitigar os impactos decorrentes das más condições de inserção urbana. Fazer uso das zonas especiais de interesse social do tipo vazios, utilizar instrumentos como os consórcios imobiliários e adotar instrumentos de combate à especulação imobiliária, vincular as demandas prioritárias definidas nos planos locais de habitação a terrenos vazios próximos habilitados ao uso residencial são algumas das medidas a serem tomadas de modo a facilitar essa interação entre as políticas urbana, habitacional e outra a elas vinculadas.

Por fim, acredita-se que a elaboração de planos de estruturação urbana para os setores em que o PMCMV passa a se concentrar corresponde a um requisito primordial a ser cumprido. Especialmente no caso das periferias, onde prevalecem os desmandos do setor imobiliário e a informalidade urbana, esses planos corresponderiam ao maior detalhamento em relação ao uso do solo, trazendo consigo diretrizes específicas de desenho urbano destinadas a solucionar problemas vinculados à distribuição demográfica, à estrutura viária, à mobilidade, às necessidades por equipamentos sociais, às demandas por infraestruturas urbanas, aos espaços livres e à delimitação das áreas de preservação permanente urbana.

\section{Renato Pequeno}

Universidade Federal do Ceará, Departamento de Arquitetura e Urbanismo, Laboratório de Estudos da Habitação. Fortaleza/CE, Brasil.

renatopequeno@gmail.com

\section{Sara Vieira Rosa}

Universidade Federal do Ceará, Departamento de Arquitetura e Urbanismo, Laboratório de Estudos da Habitação. Fortaleza/CE, Brasil.

saravrosa@yahoo.com.br 


\section{Referências}

ANCONA, A. L. e SANTA ROSA, J. (2009). Como delimitar e regulamentar zonas especiais de interesse social. Brasília, Ministério das Cidades.

ARRETCHE, M. (2012). Capacidades Administrativas dos Municípios Brasileiros para a Política Habitacional. Brasília, Ministério das Cidades.

CARDOSO, A. (2002). Política habitacional: a descentralização perversa. Cadernos Ippur. Rio de Janeiro, Ippur/DP\&A, ano XV, n. 1.

(org.) (2012). O Programa Minha Casa Minha Vida e seus efeitos territoriais. Rio de Janeiro, Letra Capital.

MARICATO, E. (2011). O impasse da política urbana no Brasil. Petrópolis, Vozes.

PEQUENO, L. R. B. (2015). Fortaleza: Transformações na ordem urbana. Rio de Janeiro, Letra Capital.

PEQUENO, L. R. B. e ROSA, S. V. (2015). Inserção urbana e segregação espacial: análise do programa Minha casa Minha Vida em Fortaleza. In: XVI ENANPUR Espaço, planejamento e insurgências. Anais. Belo Horizonte.

ROLNIK, R. et al. (org.) (2010). Como produzir moradia bem localizada com recursos do Programa Minha Casa Minha Vida. Brasília, Ministério das Cidades.

RUFINO, M. B. C. (2012). Incorporações da metrópole: centralização do capital imobiliário e nova produção do espaço em Fortaleza. Tese de Doutorado. São Paulo, Universidade de São Paulo.

SANTO AMORE, C., RUFINO, B. e SHIMBO, L. (2014). Minha Casa... E a Cidade? Avaliação do Programa Minha Casa Minha Vida em seis estados brasileiros. Rio de Janeiro, Letra Capital.

SANTORO, P. (2012). Planejar a expansão urbana: dilemas e perspectivas. Tese de Doutorado. São Paulo, Universidade de São Paulo.

SHIMBO, L. Z. (2012). Habitação social de mercado: a confluência entre Estado, empresas. Belo Horizonte, C/Arte.

Texto recebido em 14/out/2015

Texto aprovado em 10/dez/2015 
